\title{
New model of health care improve quality and reduce costs
}

\begin{abstract}
The study addresses a health care model of the elderly, focusing on the age group of the elderly, population segment in which the greatest misconceptions are identified. The current assistance models did not consider the deep transformations observed in the new epidemiological and demographic reality of the country. Considering that the aging process in Brazil is relatively recent, the article presents a proposal for a contemporary care model, recommended by the most important national and international health agencies as the most suitable for better care, focusing on the promotion, prevention of health care and the coordination of care, in order to avoid excesses, waste and fragmentation. This text is concerned with a higher quality, more resolutive and cost-effective care model.
\end{abstract}

Volume 4 Issue 4 - 2019

\section{Renato Veras}

Open University for Studies on the Elderly, State University of Rio de Janeiro, Brazil

Correspondence: Renato Veras, Open University for Studies on the Elderly, State University of Rio de Janeiro, Brazil,Tel 55021 2334-0168, Email raquelcordeirouerj@gmail.com

Received: July 12, 2019 | Published: July 26, 2019

Keywords: elderly, aging process, permanent care, cardiovascular disease

\section{Introduction}

One of mankind's greatest accomplishments has been to achieve longevity, which has been accompanied by a substantial improvement in the health parameters of populations, although these achievements have been far from equitably distributed in different countries and socioeconomic contexts. Reaching old age - once the privilege of a few - has become the norm even in the poorest countries. The challenge, therefore, is to add quality to these additional years of life. This demographic transition and the improvement in Brazil's social and economic indicators, compared to previous decades, have led to the expansion of the elderly population and greater fiscal pressure on public and private health systems. If this portion of the population increases, chronic diseases and expenditures also naturally increase. ${ }^{1}$ One of the results of this dynamic is the growing demand for health services, which can simultaneously generate scarcity and/or resource constraints. Hospital admissions become more frequent and bed occupancy times are greater than in other age groups. The diseases that affect the elderly are mostly chronic and multiple, require constant monitoring, permanent care, continuous medication and periodic examinations. ${ }^{2}$

With so many adverse situations, care of the elderly should be structured in a special manner. The current provision of health services fragments care for this age group, with multiple expert consultations, non-sharing of information and numerous drugs, clinical and imaging exams, among other procedures that overload the system, have a serious financial impact at all levels and do not generate significant benefits for health or quality of life. ${ }^{3}$

In recent decades, it has been shown that most of the public health problems affecting the population - not only communicable but also noncommunicable diseases - can be prevented. This is exemplified by the reduction in mortality due to cardiovascular disease, a reduction in the incidence and mortality of cervical cancer, the prevalence of smoking and the incidence of lung cancer in men. In summary: the burden generated by diseases can be avoided in both social and economic terms. ${ }^{4}$

The monitoring of the health conditions of a given population, as well as their associated factors, is a key instrument for guiding prevention strategies, which should aim to: favourably affect the natural history of the disease; anticipate the appearance of complications; prevent exacerbations and complications of chronic diseases; increase patient involvement in self-care; and build a database of the chronically ill, that is, the overwhelming majority of the elderly.

According to the World Health Organization (WHO), a chronic disease has one or more of the following characteristics: it is permanent, produces incapacity or disability, is caused by irreversible pathological disorders and requires long periods of supervision, observation or care. In general, chronic diseases begin slowly, have a long or uncertain duration, and do not have a single cause. ${ }^{5}$ The treatment involves changes in lifestyle and continuous care that does not usually lead to healing, but allows the disease to be kept under control and improve the patient's quality of life, in order to prevent or ameliorate functional decline. Most chronic diseases are related to age, poor eating habits, sedentary lifestyles and stress, and so can be prevented and/or delayed. It means that despite the disease, it is possible to live a fuller life for a longer time.

Programs aimed at this population should be built on the basis of integral care, with the reference health professional and their team playing a leading role, managing not the disease, but the health profile of the patient. Often, the treatment of a manifestation can only be carried out with the reduction or suspension of other actions that were being performed. ${ }^{5}$

\section{A contemporary model}

In projects outside Brazil, a general practitioner or family doctor deals with $85 \%$ to $95 \%$ of their patients, without the need of a specialist. In addition, this doctor can employ health professionals with specific training (in nutrition, physiotherapy, psychology, speech therapy, and other specialties). It is the general practitioner who makes recommendations and referrals. ${ }^{6}$

The English model, the National Health Service (NHS), employs generalist medical figures with high resolutive capabilities - so-called general practitioners (GPs) - who establish a strong bond with their patients. Access to these professionals is guaranteed to everyone regardless of income or social status, similar to the Brazilian Unified Health System (called SUS). When registering with a GP, British citizens receive free public health care in units composed of general 
practitioners and nurses. Any necessary treatment, provided it is not of extreme urgency or due to an accident, is performed there. ${ }^{7}$ The American model, on the other hand, chooses to refer patients to numerous medical specialists. These are two rich countries, with great medical traditions. However, they use different systems and produce quite different results. ${ }^{8}$

In Brazil there is an excess of consultations by specialists, as the current care model prioritizes the fragmentation of care. ${ }^{9}$ However, the discussion about population aging brought about by the new epidemiological and demographic reality suggests a need for the creation of a more resilient and effective model. ${ }^{10}$ One question therefore emerges: if everyone is discussing this issue and the solutions are already part of decision-making meetings, why is the situation unchanged? Why do leaders and managers not change the situation?

In order for the health sector-particularly in the elderly segment to reorganize itself, one of the items to consider is trust. Today society is suspicious of what is offered. In this climate, any proposal for change is viewed with reservations. Anything that is multifactorial and built over many years is difficult to transform. ${ }^{11}$ Quality of care demands greater awareness among health managers and society. It is argued that it would be expensive to apply instruments that provide more qualified care, accreditations and certifications, yet good services are more effective in terms of cost generate less waste and better patient care results. In some countries, accreditation and the evaluation of quality indicators are mandatory requirements. In Brazil, however, volume is valued and rewarded. A policy of stimulating quality is lacking. Patients do not always recognize it as a necessity. And both the public and private health systems perceive it as an additional cost.

\section{Explosive costs}

A recent study by the Organization for Economic Cooperation and Development (OECD) in developed countries shows the difference between health care costs in the United States and other rich countries which offer good quality care - where, of course, health care expenditures are greater than in developing countries. Still, the spending of the Americans is higher. In 2017, it was US\$ 10,224 per person, $28 \%$ higher than Switzerland and more than doubles the United Kingdom (Figure 1). These data reinforce the view that mass investment in disease treatment is not enough. Considering the aging of the global population, health costs tend to be an increasing burden for society, as shown in (Figure 2). This demonstrates a reduction in the costs of activities that require the use of new technologies, as opposed to costs related to hospital services. It is imperative to change the logic of care.

\section{The innovation required}

Care must be organized in an integrated manner and must be coordinated along the care path, in a network of logic, from entry into the system to care at the end of life. ${ }^{13}$ Suitable models of health care for the elderly offer a proposal for a line of care focused on actions of education, health promotion, prevention of preventable diseases, postponement of illnesses, early care and rehabilitation. ${ }^{14}$ The model should be based on the early identification of the risks of user frailty. Once risk is identified, the priority is to intervene before the event occurs, reducing the impact of chronic conditions on functionality. The idea is to monitor health, not the disease. Thus, the best strategy for proper care is to use the logic of permanent accompaniment, varying only the levels, intensity and scenario of the intervention. ${ }^{15}$

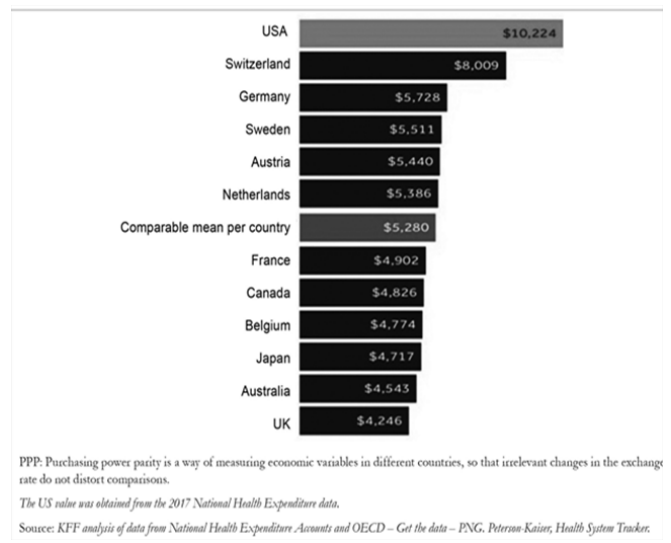

Figure I Health cost pre capita, US dollars, adjusted by purchasing power parity (PPP), 2017.

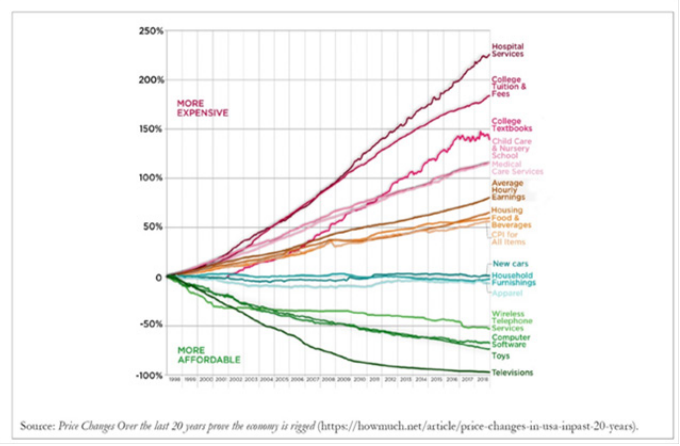

Figure 220 years of proce changes in the USA. Goods and services of selected consumers, salary (Jan 1998 to Dec. 2008)

There is a general understanding that care for the elderly goes beyond health. In addition to diagnosis and prescription, social participation, physical and mental activities are important elements for maintaining functional capacity. But especially in supplemental health, there is still much difficulty in understanding these actions as an integral part of care - a tendency to separate "social" from "healing" actions. It is also of fundamental importance, especially today, that quality information and electronic medical records register both clinical and "social" actions, and that this registry is available in the cloud and accessible by mobile, so that doctors and other health professionals can monitor the client at any time.

Regarding the remuneration model of health professionals, why not adopt performance related pay? Linking results to the form of remuneration is a powerful tool for quality of care. And the model should be of the win-win type, in which all involved benefit, especially the patients.

In order to put into practice the necessary actions for a healthy aging with a good quality of life, care for the elderly must be rethought and redesigned with a focus on these individual and their particularities. This will bring benefits, quality and sustainability not only for the elderly population but for the Brazilian health system as a whole 5 . It is time to show the capacity to unite efforts that turn theory into a 
health model of universal quality. We do not desire the fragmentation of the SUS (Brazilian Health System), nor the increase in the number of bankruptcies among private health care companies.

The challenge is to ensure this new care model is accepted by the client, as trust is an indispensable factor for the process to occur as planned-and one cannot ask someone to trust something they know nothing about. There is little point in saying that this model is the best if it is not implemented by supplementary health services. Society needs to understand this proposal extensively to be convinced of its benefits. ${ }^{16}$ Otherwise, it will continue to opt for the "siren song" of excess and consumption, which burden the system, generate ever higher costs and render long-term care unfeasible.

\section{Why are words so different our actions?}

One of the subjects of most interest is the model of healthcare available to the elderly. We are all concerned. The discussion about population aging brought about by the new epidemiological and demographic reality has (or should) lead to the development of a resolutive and effective model of health care for this group. The change in the age configuration in Brazil, with the growth of the elderly segment, is a recent phenomenon. On the other hand, we have already gone beyond the novelty stage and the clichés that are well known and today accepted by everyone-even by those who do not put them into practice. Discussing the theoretical frameworks or policies that aim to ensure healthy aging-which means maintaining functional capacity and autonomy, as well as quality of life, in line with the principles and guidelines of the Unified Health System (SUS) and focusing on disease prevention - is laudable. Major Brazilian and international health organizations have argued in favour of this idea for many years. But the next step is yet to be taken. While these words are well received by health managers and professionals, little or few of these ideas are applied. So here we must ask: if everyone is discussing the issue and the solutions are already available at the decision-making tables, why has the situation remained the same? Why does the theory not translate into everyday life? Why do leaders and managers not encourage change? Below we list some topics that will bring additional elements to the discussion. In order for the health sector - particularly the elderly segment - to reorganize itself, one item to be considered is mistrust. Today's society is suspicious of what is offered to it. In this climate, any proposal for change is viewed with reservations. Entities that are multifactorial and have been constructed over many years are difficult to transform. Changing a culture is not simple. We are aware of this problem. Another obstacle is quality of care, which remains undervalued. It is a subject of enormous importance, which demands greater awareness among health professionals and society. It is argued that it is expensive to apply instruments that improve and provide training in care, accreditations and certifications, but better qualified and trained services are more effective in terms of cost, create less waste and provide better patient care results. In some countries, accreditation and the evaluation of quality indicators are mandatory requirements. In Brazil, however, volume is valued and rewarded, while a policy that stimulates quality is lacking. Patients do not always recognize this characteristic as a necessity, and both public and private health perceive it as an additional cost.

Another issue is the general understanding that care for the elderly goes beyond health. In addition to diagnosis and prescription, social participation, physical and mental activities are important elements to maintain functionality. But we still have great difficulty in understanding these actions as an integral part of care, especially in supplemental health. There is a tendency to separate "social" from "curative" actions. It is also of fundamental importance, especially today, that quality information and medical records are effectively used by physicians and health professionals, allowing constant customer monitoring. The pay model of health professionals should also be discussed. If we accept that they are poorly paid, why do we not pay for performance? Associating the discussion of results with the form of remuneration is a powerful inductive tool in the search for what is right. Thus, "pay for performance" or "payment by results" are synonymous in the struggle for alignment between access and quality of care. The change in the remuneration model based on this new care framework, focusing on results and not volume, necessarily results in a win-win model, in which all involved benefit, but especially the patient themselves. In order to put into practice all the strategies necessary for healthy aging and quality of life, it is necessary to rethink and redesign care for the elderly, focusing on the individual and their particularities. This will bring benefits, quality and sustainability not only for the elderly population, but for the Brazilian health system as a whole. Now that we know what is required, it is time we concentrate our efforts on turning the theory into a quality health model for everyone, including the elderly. We do not want the SUS to be fragmented, or to increase the number of bankruptcies of private health care companies. One thing is certain: every year, the cost of health increases while the quality of care worsens. It is time to put into practice what everyone believes, but which we have yet to do.

\section{Conclusion}

In summary, an efficient model of health care for the elderly should involve the application of all levels of care: a well-designed flow of education, health promotion, prevention of preventable diseases, as well as the postponement of diseases and rehabilitation from illness. It begins in capitation and reception and ends only in the final moments of life, in the palliative care unit.

In order to reorient the health care of the elderly population and to organize the sector to enable better economic-financial and care results, it is sufficient that all those involved perceive themselves as responsible for change and allow themselves to innovate - which, in many situations, means rescuing simpler forms of care and values that have been lost within our health system.

We do not deny the importance of high complexity forms of care and know that we will always need good hospitals. It is not logical, however, to turn hospitals into gateways to health systems.

It is vital that the debate on healing and care is included in discussions on vocational training and the organization of services. This transformation will make a great difference at this time of population aging, as we have learned that it is possible to grow old with sustainability, stable health and a good quality of life.

\section{Funding}

None

\section{Acknowledgments}

None.

\section{Conflict of interests}

Authors declare that there is no conflict of interest. 


\section{References}

1. Veras RP, Estevam AA. Elderly health care model: the emphasis on the first level of care. In: Lozer AC, editor. Scientific and technical knowledge for qualification of supplementary health. Brasilia DF: PAHO. 2015;7384.

2. Szwarcwald CL, Damacena GN, Souza PRB, et al. Perception of the Brazilian population about the care provided by the doctor. Cienc Health Colet. 2016; 21(2):339-350.

3. Veras RP, Oliveira MR. Care line for the elderly: detailing the model. Rev Bras Geriatr Gerontol. 2016;19(6):887-905.

4. Oak VKS, Marques CP, Silva EN. The contribution of the More Doctors Program: analysis based on WHO recommendations for the provision of doctors. Cienc Saúde Colet. 2016; 21(9):2773-2784.

5. Veras RP, Oliveira MR. Aging in Brazil: the construction of a care model Cienc Health Colet. 2018;23(6):1929-1936.

6. Veras RP. Experiences and international trends of care models for the elderly. Cienc Health Colet. 2012;17(1):231--238.

7. Tanaka OR, Oliveira VE. Reform (s) and structuring of the British health system: lessons for the SUS. Health soc. 2007;16 (1):7-17.

8. Oliveira MR, Veras RP, Cordeiro A, et al. Changing care model of care for the elderly in Supplementary Health: identification of its key points and obstacles to implementation. Physis: Journal of Collective Health. 2016;26(4):1383-1394.
9. Silva AMM Juliana VMM, Sérgio VP, et al. Use of health services by Brazilian elderly with and without functional limitation. Rev Public Health. 2017;51(suppl):1-10.

10. Oliveira MR, Veras RP, Lamb HA. Supplementary Health and aging after 19 years of regulation: where are we now? Rev Bras Geriatr Gerontol. 2017;20 (5):624-633.

11. Veras RP. Caring Senior: A Brazilian model of health with emphasis on mild ainstances of care. Rev Bras Geriatr Gerontol. 2018;21(3):1-7.

12. Figueiredo JO, Prado NMBL, Medina MG, et al. Public and private health spending in Brazil and selected countries. Health in Debate. 2018;42(esp2):37-47.

13. Mendes EV. Health care networks. Brasilia: Pan american health organization; 2011.

14. Oliveira MR, Silveira DP, Araujo DV, et al. Elderly in supplementary health: an urgency for the health of society and for the sustainability of the sector. Rio de Janeiro: National agency for supplementary health; 2016.

15. Veras RZ, Caldas CP, Motta LB, et al. Integration and continuity of care in health care network models for frail older people. Rev Public Health. 2014;48(2):357-365.

16. Moraes EM. Health care of the elderly: conceptual aspects. Brasilia, DF: PAHO; 2012. 